\title{
Comparing causes of death of Hodgkin lymphoma and breast cancer patients between medical records and cause-of-death statistics
}

This article was published in the following Dove Press journal:

Clinical Epidemiology

\author{
Simone de Vries' \\ Michael Schaapveld' \\ Jan WPF Kardaun ${ }^{2,3}$ \\ Kim $\mathrm{H}$ de Bruin ${ }^{2}$ \\ Augustinus DG Krol \\ Pieternella J Lugtenburg ${ }^{5}$ \\ Judy $\mathrm{N}$ Jacobse' \\ Berthe MP Aleman ${ }^{6}$ \\ Flora E van Leeuwen' \\ 'Department of Epidemiology, \\ The Netherlands Cancer Institute, \\ Amsterdam, the Netherlands; \\ ${ }^{2}$ Department of Health and Care, \\ Statistics Netherlands, The Hague, \\ the Netherlands; ${ }^{3}$ Department of \\ Public Health, Academic Medical \\ Center, Amsterdam, the Netherlands; \\ ${ }^{4}$ Department of Radiotherapy, Leiden \\ University Medical Center, Leiden, \\ the Netherlands; ${ }^{5}$ Department of \\ Hematology, Erasmus MC Cancer \\ Institute, Rotterdam, the Netherlands: \\ ${ }^{6}$ Department of Radiation Oncology, \\ The Netherlands Cancer Institute, \\ Amsterdam, the Netherlands
}

Correspondence: Flora E van Leeuwen Department of Epidemiology, The Netherlands Cancer Institute, Plesmanlaan 121, 1066 CX Amsterdam, the Netherlands

$\mathrm{Tel}+3|205| 22483$

Fax +3I 205122322

Email f.v.leeuwen@nki.nl
Objective: Obtaining accurate data about causes of death may be difficult in patients with a complicated disease history, including cancer survivors. This study compared causes of death derived from medical records $\left(\mathrm{COD}_{\mathrm{MR}}\right)$ with causes of death derived from death certificates $\left(\mathrm{COD}_{\mathrm{DC}}\right)$ as processed by Statistics Netherlands of patients primarily treated for Hodgkin lymphoma (HL) or breast cancer (BC).

Methods: Two hospital-based cohorts comprising 1,215 HL patients who died in the period 1980-2013 and 714 BC patients who died in the period 2000-2013 were linked with cause-ofdeath statistics files. The level of agreement was assessed for common underlying causes of death using Cohen's kappa, and original death certificates were reviewed when $\mathrm{COD}_{\mathrm{DC}}$ and $\mathrm{COD}_{\mathrm{MR}}$ showed discrepancies. We examined the influence of using $\mathrm{COD}_{\mathrm{DC}}$ or $\mathrm{COD}_{\mathrm{MR}}$ on standardized mortality ratio (SMR) estimates.

Results: Agreement for the most common causes of death, including selected malignant neoplasms and circulatory and respiratory diseases, was $81 \%$ for HL patients and $97 \%$ for BC patients. $\mathrm{HL}$ was more often reported as $\mathrm{COD}_{\mathrm{DC}}\left(\mathrm{COD}_{\mathrm{DC}}=33.1 \%\right.$ vs. $\left.\mathrm{COD}_{\mathrm{MR}}=23.2 \%\right)$, whereas circulatory disease $\left(\mathrm{COD}_{\mathrm{DC}}=15.6 \%\right.$ vs. $\left.\mathrm{COD}_{\mathrm{MR}}=20.9 \%\right)$ or other diseases potentially related to $\mathrm{HL}$ treatment were more often reported as $\mathrm{COD}_{\mathrm{MR}}$. Compared to $\mathrm{SMRs}$ based on $\mathrm{COD}_{\mathrm{DC}}$, $\mathrm{SMRs}$ based on $\mathrm{COD}_{\mathrm{MR}}$ complemented with $\mathrm{COD}_{\mathrm{DC}}$ were lower for $\mathrm{HL}$ and higher for circulatory disease. Conclusion: Overall, we observed high levels of agreement between $\mathrm{COD}_{\mathrm{MR}}$ and $\mathrm{COD}_{\mathrm{DC}}$ for common causes of death in $\mathrm{HL}$ and $\mathrm{BC}$ patients. Observed discrepancies between $\mathrm{COD}_{\mathrm{MR}}$ and $\mathrm{COD}_{\mathrm{DC}}$ frequently occurred in the presence of late effects of treatment for HL.

Keywords: cause of death, Hodgkin lymphoma, breast cancer, mortality statistics

\section{Introduction}

In epidemiology, differences in mortality risks between patient cohorts and the general population are usually quantified using standardized mortality ratios (SMRs). SMR estimation requires the availability of age-, sex-, and period-specific mortality rates for the general population. Often, these mortality rates are available from nationwide registries. It is therefore important that mortality data from official death certificates reflect similar underlying cause-of-death patterns as cause-of-death information from medical records. Inconsistencies in processing of causes of death may have implications for the interpretation of SMRs in epidemiologic studies. Only few studies compared cause-of-death information from medical records or hospital discharge records with death certificates. ${ }^{1-5}$

In recent years, it has become challenging to obtain cause-of-death information in cancer survivor cohorts, especially in case of mortality long after initial cancer 
treatment. Patients are more often cured and discharged, may have changed addresses, and may have died in another hospital, hospice or at home. Furthermore, due to the increasing administrative burden on general practitioners (GPs), response rates of clinical follow-up questionnaires have dropped considerably. To complete information on causes of death, linkage with a national cause-of-death registry can be considered. However, accurate registration of causes of death may be more difficult in patients with a long interval between disease diagnosis and date of death or a complicated disease history. For example, Hodgkin lymphoma (HL) patients are generally young at the time of treatment and have an excellent prognosis. Yet, they have an increased risk to die from various late adverse events related to treatment, including among others, second malignancies, cardiovascular diseases, and infections. ${ }^{6,7}$ These late complications may affect cause-of-death coding in these patients. In contrast, breast cancer $(\mathrm{BC})$ patients also have a good prognosis but a lower risk of adverse effects of treatment, ${ }^{8}$ which may lead to less inconsistency in cause-of-death coding. For the interpretation of epidemiological studies on cause-specific mortality, it is important to gain insight into the effects of using cause-of-death information from different sources in different populations of cancer survivors.

In this study, we therefore compared causes of death recorded in the medical files with cause-of-death information from death certificates as processed by the Dutch cause-ofdeath statistics (Statistics Netherlands) in patients treated for HL or BC. We also examined to what extent differences in classification of causes of death influence SMRs.

\section{Methods}

We used data from a hospital-based cohort of HL patients $(n=3,019)$, treated in the Antoni van Leeuwenhoek hospital, Erasmus MC Cancer Institute or Leiden University Medical Center, between 1965 and 2000, before the age of 51 years, and data from a hospital-based cohort of female BC patients $(n=5,600)$ treated in the Antoni van Leeuwenhoek hospital for stages I-III invasive BC between 2000 and 2009, before the age of 61 years. Patient selection and data collection have been described in detail previously. ${ }^{6,9-11,14}$ For the comparison of causes of death, we considered all 1,215 HL patients who died in the period 1980-2013 and all 714 BC patients who died in the period 2000-2013.

Causes of death for both HL and BC patients were obtained from hospital medical records by trained abstractors. If abstractors had difficulties in assigning a cause of death, the patient was discussed within the project team (MS,
BMPA, FEvL, SdV, JNJ) until agreement was reached. If the cause of death could not be retrieved from the hospital charts, a questionnaire was sent to the patient's GP regarding the patient's medical history and direct and underlying causes of death. Response rates from the GPs were 94\% in $2004^{11,12}$ and $83 \%$ in 2012 for the HL cohort ${ }^{13}$ and $71 \%$ in 2016 for the BC cohort. ${ }^{14}$ Exact dates of death were confirmed through linkage with the Central Office of Genealogy in order to allow deterministic linkage of all cohort members with Statistics Netherlands. This study was exempt from the approval of institutional review board according to Dutch law because existing data from medical files were used, which was confirmed by the institutional review board of the Netherlands Cancer Institute (PTC17.0788). Questionnaires obtained from the GPs were anonymized for the researchers, as well as the data retrieved from the hospital medical records. All analyses were performed at Statistics Netherlands: no cause-of-death registry data were exchanged. Original death certificates at Statistics Netherlands were reviewed by SdV only under a confidentiality agreement.

In the Netherlands, the underlying cause of death for each decedent is registered by Statistics Netherlands. Attending physicians or medical examiners are obliged to fill out a death certificate, which is sent to Statistics Netherlands through the municipality where the death occurred. At Statistics Netherlands, the death certificates are coded and an underlying cause is selected according to the tenth revision of the ICD (ICD-10), with a maximum of four coded diseases per decedent. The ICD-10 defines the underlying cause of death as 1) the disease or injury that initiated the train of morbid events leading directly to death or 2) the circumstances of the accident or violence that produced the fatal injury, with Volume 2 of ICD-10 providing several instructions for the application of this definition. ${ }^{15}$ Detailed information on methods of registration of causes of death in the Netherlands has been published previously. ${ }^{16,17}$

The hospital-based cohorts of HL and BC patients were linked with the causes of death at Statistics Netherlands to enable comparison of the causes of death derived from the medical records $\left(\mathrm{COD}_{\mathrm{MR}}\right)$ with causes of death derived from the death certificates $\left(\mathrm{COD}_{\mathrm{DC}}\right)$. Individual-level linkage was based on sex, date of birth, date of death, and filing municipality (first linkage step). If linkage failed due to missing information on filing municipality in the cohort data, linkage was based on the remaining three variables (second linkage step). Additionally, we performed a third linkage procedure where we varied parts of the linkage key (eg, day of death or day of birth). By chance, it is possible that two individuals 
have an identical linkage key $(0.05 \%$ of total on the first linkage step and $1.3 \%$ on the second linkage step in the period 1980-2013). However, we checked for duplicate matches in both cohorts on the first two linkage keys and found none. Linkage was successful for 1,140 deceased patients (93.8\%) in the HL cohort and 690 deceased patients $(96.6 \%)$ in the BC cohort. The difference in successful linkages can be understood when realizing that deaths within the HL cohort partly occurred in earlier decades.

\section{Statistical analyses}

We compared the $\mathrm{COD}_{\mathrm{MR}}$ and the $\mathrm{COD}_{\mathrm{DC}}$ for common causes of death according to the ICD-10, including malignant neoplasms and circulatory disease, for all patients who were successfully linked with Statistics Netherlands. The causes of death of patients for whom the cause of death in our cohort was missing (unable to retrieve from the medical records and no response from the GP), or unspecified (ICD-10 codes R96-R99) were categorized as unknown or unavailable, including for 373 deceased HL patients (32.2\%) and 113 deceased $\mathrm{BC}$ patients (16.4\%). We calculated the conditional agreement between the $\mathrm{COD}_{\mathrm{MR}}$ and the $\mathrm{COD}_{\mathrm{DC}}$ in patients for whom the cause of death was available from both sources, thus excluding patients with unknown or unavailable cause of death. Conditional agreement for medical records was defined as the number of deceased patients for whom $\mathrm{COD}_{\mathrm{MR}}$ was in agreement with $\mathrm{COD}_{\mathrm{DC}}$ divided by the total number of deaths from a specific cause according to $\mathrm{COD}_{\mathrm{MR}}$ and vice versa for the conditional agreement for death certificates. Overall agreement between $\mathrm{COD}_{\mathrm{MR}}$ and $\mathrm{COD}_{\mathrm{DC}}$ was calculated by dividing the number of patients for whom the causes of death from $\mathrm{COD}_{\mathrm{MR}}$ and $\mathrm{COD}_{\mathrm{DC}}$ agreed by the total number of deceased patients. To adjust for chance agreement, the Cohen's kappa statistic was calculated. Kappa values of $>0.75$ were considered to represent excellent agreement, values of $0.40-0.75$ represented moderate agreement, and values of $<0.40$ represented poor agreement. ${ }^{18}$

The original death certificates were reviewed when $\mathrm{COD}_{\mathrm{MR}}$ differed from $\mathrm{COD}_{\mathrm{DC}}$. Discrepancies were examined when $\mathrm{HL}$ was coded as $\mathrm{COD}_{\mathrm{MR}}$ but not as $\mathrm{COD}_{\mathrm{DC}}$, or vice versa, in the HL cohort. Similarly, discrepancies were further examined when $\mathrm{BC}$ was coded as $\mathrm{COD}_{\mathrm{MR}}$ and but not as $\mathrm{COD}_{\mathrm{DC}}$, or vice versa, in the $\mathrm{BC}$ cohort. Additionally, discrepancies between $\mathrm{COD}_{\mathrm{MR}}$ and $\mathrm{COD}_{\mathrm{DC}}$ were investigated when in the HL cohort, both $\mathrm{COD}_{\mathrm{MR}}$ and $\mathrm{COD}_{\mathrm{DC}}$ concerned a common malignancy as cause of death (including lung cancer, gastrointestinal cancer, non-HL and leukemia) or when $\mathrm{COD}_{\mathrm{MR}}$ was recorded as a common malignancy and $\mathrm{COD}_{\mathrm{DC}}$ specified circulatory disease, or vice versa. For examination of such discrepancies, only original death certificates filed between 1980-1989 and 2000-2013 were accessible.

Finally, we assessed whether and to what extent discrepancies in causes of death influenced the results of personyear analyses of cause-specific mortality. We compared the observed mortality in our HL cohort and mortality in the general population, taking into account the person-years of observation of patients in our cohort by age, sex, and calendar period. Mortality data for the general population from Statistics Netherlands for the period 1980-2013 were used as reference rates. In this analysis, time at risk began at start of treatment and ended at date of death, date of emigration, or December 31, 2013, whichever came first. SMRs were calculated as the ratio of the observed and expected number of deaths in our HL cohort, and the confidence limits were calculated using exact Poisson probabilities of observed numbers. The absolute excess risk (AER) was calculated as the observed minus the expected number of deaths divided by person-years at risk, expressed per 10,000 person-years. First, we performed the analysis using $\mathrm{COD}_{\mathrm{MR}}$ supplemented by $\mathrm{COD}_{\mathrm{DC}}$ if $\mathrm{COD}_{\mathrm{MR}}$ was missing. Subsequently, we performed the analysis using only $\mathrm{COD}_{\mathrm{DC}}$. Lastly, we performed the analysis in the same way as the first analysis, and we additionally supplemented $\mathrm{COD}_{\mathrm{MR}}$ with $\mathrm{COD}_{\mathrm{DC}}$ if the data between the two sources showed discrepancy.

\section{Results}

In total, we included 1,140 deceased HL patients and 690 deceased BC patients for whom linkage with Statistics Netherlands could be performed. Table 1 shows the descriptive characteristics of both patient groups. The majority of deceased HL patients were male (61.8\%). Median age at primary cancer diagnosis was 30.4 years (interquartile range $[\mathrm{IQR}]=23.7-38.6$ ) for $\mathrm{HL}$ patients and 50.3 years ( $\mathrm{IQR}=42.7-55.6)$ for $\mathrm{BC}$ patients. For HL patients, the median interval between HL treatment and death was 17.4 (IQR=8.0-27.0), and for BC patients, this interval was 4.3 years $(\mathrm{IQR}=2.4-6.8)$. Cause of death was available from both the medical records and death certificates for $767 \mathrm{HL}$ patients and $577 \mathrm{BC}$ patients.

The level of agreement between medical records and death certificates for common causes of death in HL patients (including HL; breast, lung, and gastrointestinal cancers; non-HL and leukemia; other malignant neoplasms; circulatory disease; and respiratory disease) is shown in Table 2. Using either $\mathrm{COD}_{\mathrm{MR}}$ or $\mathrm{COD}_{\mathrm{DC}}$, the majority of patients died from a malignant neoplasm $(66.5 \%$ and $75.9 \%$, 
Table I Descriptive characteristics of deceased $\mathrm{HL}$ and $\mathrm{BC}$ patients

\begin{tabular}{lll}
\hline Characteristics & HL, $\mathbf{n}(\%)$ & BC, $\mathbf{n}(\%)$ \\
\hline Total cohort & $1,140(100)$ & $690(100)$ \\
Females in cohort & $435(38.2)$ & $690(100)$ \\
Calendar period of cancer diagnosis & & \\
1965-1979 & $598(52.5)$ & \\
1980-1989 & $380(33.3)$ & $690(100)$ \\
1990-2000 & $162(14.2)$ & $50.3(42.7-55.6)$ \\
2000-2009 & & $54.9(47.4-61.0)$ \\
Age at diagnosis of cancer, median (IQR) & $30.4(23.7-38.6)$ & $4.3(2.4-6.8)$ \\
Age at death, median (IQR) & $50.3(38.8-59.7)$ & \\
Time interval between cancer diagnosis and death, median (IQR) & $17.4(8.0-27.0)$ & \\
Calendar period of death & & \\
1980-1989 & $288(25.3)$ & $336(29.5)$ \\
1990-1999 & $516(45.3)$ & $690(100)$ \\
$\geq 2000$ & & \\
\hline Ab & & \\
\hline
\end{tabular}

Abbreviations: $\mathrm{HL}$, Hodgkin lymphoma; $\mathrm{BC}$, breast cancer; IQR, interquartile range.

Table 2 Level of agreement between causes of death from medical records and death certificates in $\mathrm{HL}$ patients

\begin{tabular}{llllll}
\hline Cause of death & $\begin{array}{l}\text { Number of deaths } \\
\text { according to } \\
\text { medical records (\%) }\end{array}$ & $\begin{array}{l}\text { Number of deaths } \\
\text { according to death } \\
\text { certificates (\%) }\end{array}$ & $\begin{array}{l}\text { Conditional } \\
\text { agreement in medical } \\
\text { records }^{\mathbf{a}} \text { (\%) }\end{array}$ & $\begin{array}{l}\text { Conditional } \\
\text { agreement in death } \\
\text { certificates }^{\mathbf{b}}(\%)\end{array}$ \\
\hline Malignant neoplasm & $510(66.5)$ & $582(75.9)$ & 96.5 & 84.5 & $\begin{array}{l}\text { Cohen's } \\
\text { kappa }\end{array}$ \\
Gastrointestinal cancer & $70(9.1)$ & $76(9.9)$ & 88.6 & 81.6 & 0.66 \\
Lung cancer & $88(11.5)$ & $93(12.1)$ & 84.1 & 79.6 & 0.83 \\
BC & $26(3.4)$ & $31(4.0)$ & 100 & 83.9 & 0.79 \\
HL & $178(23.2)$ & $254(33.1)$ & 89.9 & 63.0 & 0.91 \\
Circulatory disease & $160(20.9)$ & $120(15.6)$ & 63.8 & 85.0 & 0.64 \\
Ischemic heart disease & $45(5.9)$ & $56(7.3)$ & 57.8 & 46.4 & 0.67 \\
Other heart diseases & $83(10.8)$ & $24(3.1)$ & 18.1 & 62.5 & 0.48 \\
\hline
\end{tabular}

Notes: Cause of death according to the ICD-I0: malignant neoplasms (C00-C97), gastrointestinal cancer (CI5-C26), lung cancer (C33-C34), BC (C50), HL (C8I),

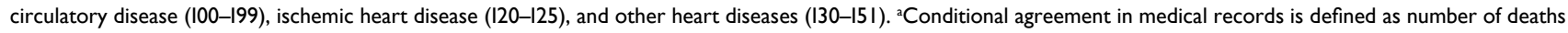
in agreement with death certificates divided by the total number of deaths from a specific cause of death. ${ }^{b}$ Conditional agreement in death certificates is defined as number of deaths in agreement with medical records divided by the total number of deaths from a specific cause of death.

Abbreviations: HL, Hodgkin lymphoma; BC, breast cancer.

respectively). According to $\mathrm{COD}_{\mathrm{MR}}, 23.2 \%$ of all patients died from $\mathrm{HL}$ compared to $33.1 \%$ according to $\mathrm{COD}_{\mathrm{DC}}$. When the $\mathrm{COD}_{\mathrm{DC}}$ stated HL, only in $63 \%$ of deaths, $\mathrm{COD}_{\mathrm{DC}}$ and $\mathrm{COD}_{\mathrm{MR}}$ agreed. The conditional agreement for $\mathrm{HL}$ as $\mathrm{COD}_{\mathrm{MR}}$ was $89.9 \%$, while the corresponding Cohen's kappa value of 0.64 indicated moderate agreement. On the other hand, for breast, lung, and gastrointestinal cancers, excellent agreement was observed between $\mathrm{COD}_{\mathrm{MR}}$ and $\mathrm{COD}_{\mathrm{DC}}$ in HL patients (corresponding Cohen's kappa: 0.91, 0.79, and 0.83 , respectively). HL patients more often died from cardiovascular disease according to $\mathrm{COD}_{\mathrm{MR}}$ than according to $\mathrm{COD}_{\mathrm{DC}}(20.9 \%$ vs. $15.6 \%$, respectively). For ischemic heart disease, the conditional agreement was $57.8 \%$ for $\mathrm{COD}_{\mathrm{MR}}$ and $46.4 \%$ for $\mathrm{COD}_{\mathrm{DC}}$, with a corresponding kappa value of 0.48 . The conditional agreement for other heart diseases was low for $\mathrm{COD}_{\mathrm{MR}}(18.1 \%)$, and the corresponding kappa value of 0.24 reflected poor level of agreement between $\mathrm{COD}_{\mathrm{MR}}$ and $\mathrm{COD}_{\mathrm{DC}}$. The overall agreement between $\mathrm{COD}_{\mathrm{MR}}$ and $\mathrm{COD}_{\mathrm{DC}}$ for common causes of death in HL patients was $81.4 \%$, excluding other, unknown, and unavailable causes of death (Table 3). Including all other causes of death, the overall agreement was $70.8 \%$. Among patients for whom the $\mathrm{COD}_{\mathrm{DC}}$ was HL, 29 out of 365 patients died from non-HL or leukemia according to $\mathrm{COD}_{\mathrm{MR}}$. Similarly, 10 out of 180 patients who died of $\mathrm{HL}$ according to $\mathrm{COD}_{\mathrm{MR}}$, died from non-HL or leukemia according to $\mathrm{COD}_{\mathrm{DC}}$. Additionally, a substantial part of HL patients who died of HL according to $\mathrm{COD}_{\mathrm{DC}}$ died from circulatory disease according to $\mathrm{COD}_{\mathrm{MR}}$ (22 out of 164 patients).

In addition in $\mathrm{BC}$ patients, malignant neoplasm was the most important cause of death (Table 4). When the $\mathrm{COD}_{\mathrm{MR}}$ was $\mathrm{BC}$, in $95.4 \%$ of deaths, the $\mathrm{COD}_{\mathrm{DC}}$ was also $\mathrm{BC}$, 


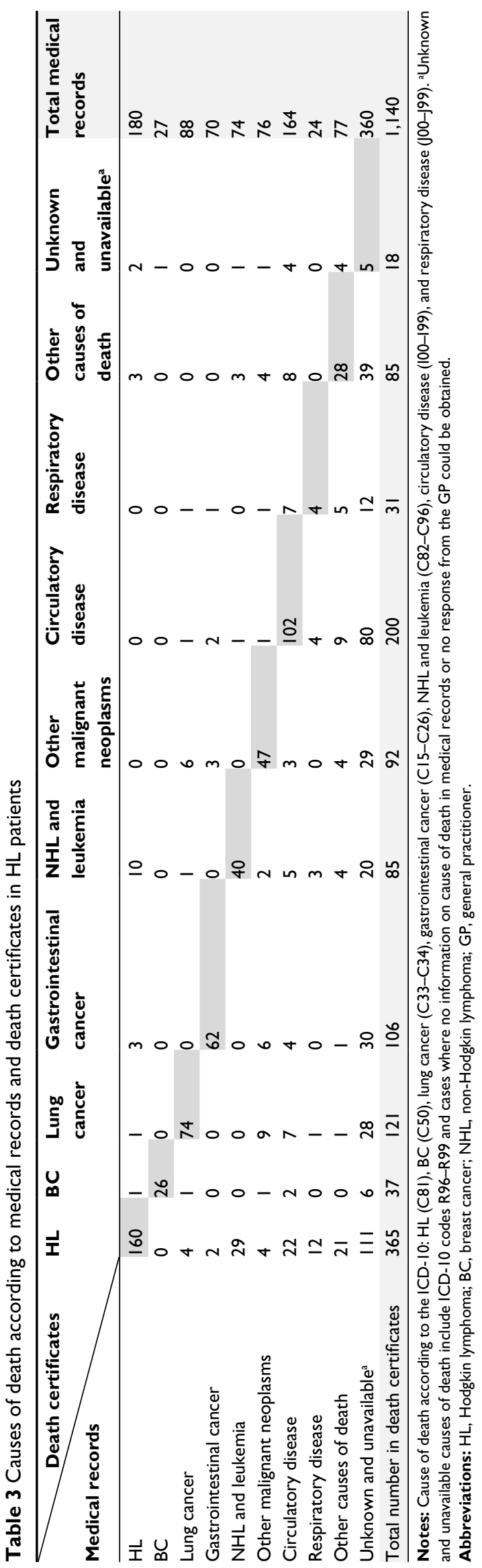

resulting in a conditional agreement in $\mathrm{COD}_{\mathrm{DC}}$ of $95.0 \%$. The corresponding Cohen's kappa value of 0.75 indicated high agreement between $\mathrm{COD}_{\mathrm{MR}}$ and $\mathrm{COD}_{\mathrm{DC}}$. Kappa values also indicated excellent agreement between $\mathrm{COD}_{\mathrm{MR}}$ and $\mathrm{COD}_{\mathrm{DC}}$ for lung cancer (0.78) and gastrointestinal cancer (0.80) in $\mathrm{BC}$ patients. For $\mathrm{BC}$ patients, a higher overall agreement between $\mathrm{COD}_{\mathrm{MR}}$ and $\mathrm{COD}_{\mathrm{DC}}$ for common causes of death was observed compared to HL patients (Table S1). Here, the overall agreement for breast, lung, and gastrointestinal cancers; other malignant neoplasms; and circulatory disease was $96.6 \%$. Including other causes of death, the overall agreement was $91.7 \%$.

For 70 out of 109 deceased $\mathrm{HL}$ patients for whom $\mathrm{COD}_{\mathrm{MR}}$ and $\mathrm{COD}_{\mathrm{DC}}$ differed, death certificates were filed in the years that were available for review (Table 5). When $\mathrm{COD}_{\mathrm{MR}}$ was attributed to HL, seven discrepancies were due to the lack of specification by the physician, eg, NHL or "lymphoma" was stated on the death certificate rather than HL, and three discrepancies reflected coding errors by the registration clerk. When $\mathrm{COD}_{\mathrm{DC}}$ was recorded as HL, 16 discrepancies were caused by the fact that the physician filing the death certificate related the cause of death to late adverse events of treatment for HL, which was, however, diagnosed $>10$ years prior to death in patients cured of HL, eg, "lung fibrosis after radiotherapy for the treatment of HL" was stated on the death certificate.

For 41 out of 42 deceased $\mathrm{BC}$ patients for whom we observed discrepancies between $\mathrm{COD}_{\mathrm{MR}}$ and $\mathrm{COD}_{\mathrm{DC}}$, death certificates were available for review (Table S2). Of the 21 deaths attributed to $\mathrm{BC}$ in the $\mathrm{COD}_{\mathrm{MR}}$ but not in the $\mathrm{COD}_{\mathrm{DC}}$, the discrepancy was once due to a coding error and the $\mathrm{COD}_{\mathrm{DC}}$ was once attributed to an external cause of death without $\mathrm{BC}$ being mentioned on the death certificate. No explanation could be found for the remaining 19 discrepancies. In none of the 20 discrepancies where $\mathrm{COD}_{\mathrm{DC}}$ was attributed to $\mathrm{BC}$ while the $\mathrm{COD}_{\mathrm{MR}}$ was recorded as another disease, an explanation could be found.

Table 6 shows the results of the person-year analysis of cause-specific mortality for common causes of death in HL patients, using $\mathrm{COD}_{\mathrm{MR}}$ complemented with $\mathrm{COD}_{\mathrm{DC}}$ when $\mathrm{COD}_{\mathrm{MR}}$ was missing and, alternatively, using $\mathrm{COD}_{\mathrm{DC}}$ only. Compared to SMRs based on $\mathrm{COD}_{\mathrm{DC}}$ only, SMRs based on $\mathrm{COD}_{\mathrm{MR}}$ complemented with $\mathrm{COD}_{\mathrm{DC}}$ were higher for circulatory disease $(\mathrm{SMR}=5.9 ; 95 \% \mathrm{CI}=5.2-6.6$ vs. $\mathrm{SMR}=4.6 ; 95 \%$ $\mathrm{CI}=4.0-5.2, P<0.05)$. Conversely, SMRs were lower for HL ( $\mathrm{SMR}=1,030 ; 95 \% \mathrm{CI}=917-1,152$ vs. $\mathrm{SMR}=1,249 ; 95 \%$ $\mathrm{CI}=1,124-1,384, P<0.05)$. These differences are reflected in the AERs as well, especially for HL as cause of death. 
Table 4 Level of agreement between causes of death from medical records and death certificates in BC patients

\begin{tabular}{llllll}
\hline Cause of death & $\begin{array}{l}\text { Number of deaths } \\
\text { according to medical } \\
\text { records (\%) }\end{array}$ & $\begin{array}{l}\text { Number of deaths } \\
\text { according to death } \\
\text { certificates (\%) }\end{array}$ & $\begin{array}{l}\text { Conditional } \\
\text { agreement in medical } \\
\text { records } \text { (\%) }^{\text {real }}\end{array}$ & $\begin{array}{l}\text { Conditional } \\
\text { agreement in death } \\
\text { certificates }^{\mathbf{b}} \text { (\%) }\end{array}$ \\
\hline Malignant neoplasm & $544(94.3)$ & $554(96.0)$ & 99.1 & 96.6 & 0.63 \\
kastrointestinal cancer & $12(2.1)$ & $18(3.1)$ & 100 & 66.7 & 0.80 \\
Lung cancer & $22(3.8)$ & $29(5.0)$ & 90.9 & 69.0 & 0.78 \\
BC & $478(82.8)$ & $476(82.5)$ & 95.4 & 95.0 & 0.75 \\
Circulatory disease & II (I.9) & $4(0.7)$ & 36.4 & 100 & 0.53 \\
\hline
\end{tabular}

Notes: Cause of death according to the ICD-10: malignant neoplasms (C00-C97), gastrointestinal cancer (C15-C26), lung cancer (C33-C34), BC (C50), and circulatory

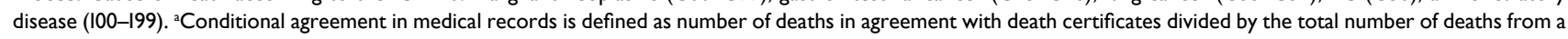
specific cause of death. ${ }^{b}$ Conditional agreement in death certificates is defined as number of deaths in agreement with medical records divided by the total number of deaths from a specific cause of death.

Abbreviation: $\mathrm{BC}$, breast cancer.

Table 5 Causes of discrepancies between causes of death from medical records and causes of death from death certificates in HL patients

\begin{tabular}{|c|c|c|}
\hline n & $\%$ & Comments \\
\hline \multicolumn{3}{|c|}{$\mathrm{HL}$ as cause of death from medical records, other cause of death based on death certificates } \\
\hline 10 & 66 & Coding or filing error \\
\hline 7 & 47 & Filing error on death certificate (physician stated "NHL" or "lymphoma") \\
\hline 3 & 20 & Coding error by registration clerk \\
\hline 2 & 13 & External cause of death \\
\hline I & 7 & Cause of death from medical records mentioned on death certificate ${ }^{a}$ \\
\hline I & 7 & Cause of death from death certificates registered in medical records ${ }^{b}$ \\
\hline 3 & 20 & No explanation ${ }^{c}$ \\
\hline 2 & 13 & Malignant neoplasm stated as cause of death on death certificate, not registered in medical records \\
\hline I & 7 & Malignant neoplasm stated as cause of death on death certificate, registered in medical records \\
\hline 3 & 20 & Cause of death from medical records not stated on death certificate \\
\hline 15 & 100 & \\
\hline \multicolumn{3}{|c|}{$\mathrm{HL}$ as cause of death from death certificates, other causes of death based on medical records } \\
\hline 16 & 29 & Physician relates cause of death to HL diagnosis $>10$ years prior to death ${ }^{d}$ \\
\hline 7 & 34 & Cause of death from medical records stated on death certificate, but not as underlying cause of deathe \\
\hline 4 & 7 & Cause of death from medical records related to diagnosis stated on death certificate \\
\hline 5 & 9 & Cause of death from medical records not stated on death certificate \\
\hline 39 & 71 & No explanation \\
\hline 15 & 27 & Cause of death from medical records stated on death certificate, but not as underlying cause of death \\
\hline 7 & 13 & Cause of death from medical records related to diagnosis stated on death certificate ${ }^{f}$ \\
\hline 17 & 31 & Cause of death from medical records not stated on death certificate \\
\hline 55 & 100 & \\
\hline
\end{tabular}

Notes: ${ }^{a}$ The death certificate stated that the patient committed suicide because there were no further options for the treatment of HL. ${ }^{\mathrm{b}}$ The death certificate stated that the patient had euthanasia for BC. "Numbers do not add up to $100 \%$; multiple comments possible when no explanation was found. ${ }^{\mathrm{d}}$ The physician stated on the death certificate:

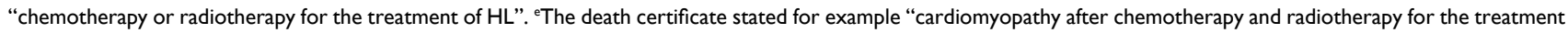
of HL". 'The death certificate stated for example "heart failure", whereas the medical records stated "cardiomyopathy".

Abbreviations: HL, Hodgkin lymphoma; NHL, non-Hodgkin lymphoma; BC, breast cancer.

The SMRs in the person-year analysis, where we complemented $\mathrm{COD}_{\mathrm{MR}}$ with $\mathrm{COD}_{\mathrm{DC}}$ and where we supplemented $\mathrm{COD}_{\mathrm{MR}}$ with $\mathrm{COD}_{\mathrm{DC}}$ when these causes of death showed discrepancy, approximated the results of the analysis where we used $\mathrm{COD}_{\mathrm{DC}}$ only.

\section{Discussion}

Overall, we observed high agreement when comparing causes of death from medical records and death certificates. Among
HL patients, an overall agreement of $81 \%$ was observed for common causes of death. However, $\mathrm{COD}_{\mathrm{MR}}$ more often stated cardiovascular disease, whereas $\mathrm{COD}_{\mathrm{DC}}$ was more often recorded as HL. Differences between $\mathrm{COD}_{\mathrm{MR}}$ and $\mathrm{COD}_{\mathrm{DC}}$ were much smaller for $\mathrm{BC}$ patients. The majority of $\mathrm{BC}$ patients died from $\mathrm{BC}$ itself, and a high overall agreement (97\%) was observed between $\mathrm{COD}_{\mathrm{MR}}$ and $\mathrm{COD}_{\mathrm{DC}}$. We compared SMRs based on different sources of data in our HL cohort and observed a lower SMR for HL and a higher SMR 
Table 6 Person-year analysis on cause-specific mortality using different cause-of-death data in HL patients

\begin{tabular}{|c|c|c|c|c|c|c|c|c|c|c|c|c|}
\hline \multirow[t]{2}{*}{ Cause of death } & \multicolumn{4}{|c|}{$\begin{array}{l}\text { Observed causes of death from } \\
\text { medical records, complemented } \\
\text { with death certificates }^{\mathrm{a}}\end{array}$} & \multicolumn{4}{|c|}{$\begin{array}{l}\text { Observed causes of death } \\
\text { from death certificates onlyb }\end{array}$} & \multicolumn{4}{|c|}{$\begin{array}{l}\text { Observed causes of death from } \\
\text { medical records, discrepancies } \\
\text { supplemented with death } \\
\text { certificates }^{c}\end{array}$} \\
\hline & 0 & $E$ & $\begin{array}{l}\text { SMR } \\
(95 \% \mathrm{Cl})\end{array}$ & AER & 0 & $\mathbf{E}$ & $\begin{array}{l}\text { SMR } \\
(95 \% \mathrm{Cl})\end{array}$ & AER & 0 & $\mathbf{E}$ & $\begin{array}{l}\text { SMR } \\
(95 \% \mathrm{Cl})\end{array}$ & AER \\
\hline Malignant neoplasms & 743 & 69.8 & $10.6(10.0-11.6)$ & 129.3 & 804 & 69.8 & $11.5(10.7-12.3)$ & 141.0 & 828 & 69.8 & $11.9(11.1-12.7)$ & 145.6 \\
\hline Gastrointestinal cancer & 105 & 18.4 & $5.7(4.7-6.9)$ & 16.6 & 108 & 18.4 & $5.9(4.8-7.0)$ & 17.2 & 111 & 18.4 & $6.0(5.0-7.2)$ & 17.8 \\
\hline Lung cancer & 120 & 18.4 & $6.5(5.4-7.8)$ & 19.5 & 121 & 18.4 & $6.6(5.5-7.9)$ & 19.7 & 125 & 18.4 & $6.8(5.7-8.1)$ & 20.5 \\
\hline $\mathrm{BC}$ & 34 & 7.4 & $4.6(3.2-6.4)$ & 5.1 & 37 & 7.4 & $5.0(3.5-6.9)$ & 5.7 & 38 & 7.4 & $5.1(3.6-7.0)$ & 5.9 \\
\hline $\mathrm{HL}$ & 301 & 0.3 & $\begin{array}{l}1,029.7 \\
(916.6-1,152.8)\end{array}$ & 57.8 & 365 & 0.3 & $\begin{array}{l}I, 248.6 \\
(I, 123.8-1,383.5)^{d}\end{array}$ & 70.1 & 368 & 0.3 & $\begin{array}{l}1,258.9 \\
(1,133.5-1,394.3)\end{array}$ & 70.6 \\
\hline $\mathrm{NHL}$ & 50 & 2.0 & $24.6(18.2-32.4)$ & 9.2 & 60 & 2.0 & $29.5(22.5-38.0)$ & 11.1 & 67 & 2.0 & $32.9(25.5-41.8)$ & 12.5 \\
\hline Leukemia & 29 & 1.9 & $15.0(10.0-21.5)$ & 5.2 & 23 & 1.9 & $11.9(7.5-17.8)$ & 4.0 & 24 & 1.9 & $12.4(8.0-18.5)$ & 4.2 \\
\hline $\begin{array}{l}\text { Infectious and parasitic } \\
\text { diseases }\end{array}$ & 32 & 2.6 & $12.4(8.4-\mid 7.4)$ & 5.6 & 16 & 2.6 & $6.2(3.5-10.0)$ & 2.6 & 18 & 2.6 & $6.9(4.1-11.0)$ & 3.0 \\
\hline Circulatory disease & 257 & 43.8 & $5.9(5.2-6.6)$ & 41.0 & 200 & 43.8 & $4.6(4.0-5.2)^{d}$ & 30.0 & 213 & 43.8 & $4.9(4.2-5.6)$ & 32.5 \\
\hline Respiratory disease & 37 & 8.0 & $4.6(3.2-6.4)$ & 5.6 & 31 & 8.0 & $3.9(2.6-5.5)$ & 4.4 & 32 & 8.0 & $4.0(2.7-5.6)$ & 4.6 \\
\hline
\end{tabular}

Notes: aCause of death was based on information from the medical records and supplemented with information from death certificates when the cause of death was unknown or unavailable from the medical records. ${ }^{b} \mathrm{C}$ ause of death was based on information from the death certificates only. ${ }^{c} \mathrm{Cause}$ of death was based on information from the medical records and supplemented with information from death certificates when the cause of death was unknown or unavailable from the medical records or when the cause of death was discrepant between the medical records and death certificates. 'Statistical comparison between SMRs from the analysis using observed causes of death from medical records complemented with death certificates and using observed causes of death from death certificates only showed a statistically significant difference at a $P$-value of $<0.05$. Here, we assumed that the covariance between the different SMRs was zero. Since the two samples were not independent, covariance will be positive, resulting in a smaller $P$-value. Comparisons remain inconclusive when we observe a nonstatistically significant difference between SMRs at a covariance of zero.

Abbreviations: HL, Hodgkin lymphoma; NHL, non-Hodgkin lymphoma; O, observed; E, expected; SMR, standardized mortality ratio; AER, absolute excess risk.

for circulatory disease when using $\mathrm{COD}_{\mathrm{MR}}$ complemented with $\mathrm{COD}_{\mathrm{DC}}$ compared to using $\mathrm{COD}_{\mathrm{DC}}$ only. We only calculated SMRs for the HL cohort, since very few discrepancies were observed for common causes of death in the $\mathrm{BC}$ cohort, and only a small number of missing causes of death from the medical records would need to be complemented with the causes of death from the death certificate. Therefore, we do not expect to find more than minor differences in the calculated SMRs in the BC cohort. We assessed discrepancies at an individual level by reviewing original death certificates when differences were observed between $\mathrm{COD}_{\mathrm{MR}}$ and $\mathrm{COD}_{\mathrm{DC}}$. However, no explanations could be found for most of these discrepancies. In our study, linkage errors are minimal and we do not expect that these errors explain the observed discrepancies. Part of the discrepancies between $\mathrm{COD}_{\mathrm{MR}}$ and $\mathrm{COD}_{\mathrm{DC}}$ in $\mathrm{HL}$ patients could be explained by the fact that the physician attributed the cause of death on the death certificate to a potential late adverse effect of treatment for HL. However, as the patient was cured of HL according to the medical record, recording of $\mathrm{HL}$ as a cause of death does not seem to be correct. In addition, for an individual patient, causality of an exposure-disease sequence can never be established. Here, we must keep in mind that $\mathrm{COD}_{\mathrm{MR}}$ and $\mathrm{COD}_{\mathrm{DC}}$ are collected for different purposes. In research focusing on the prognosis of HL or long-term adverse events of HL treatment, it is undesirable to code HL as the underlying cause of death when a patient is cured of $\mathrm{HL}$ and dies from a potential late effect of HL treatment. For example, when a physician states "cardiomyopathy as a consequence of chemotherapy for the treatment of HL", the $\mathrm{COD}_{\mathrm{DC}}$ will be coded as HL, whereas in late effects research, the $\mathrm{COD}_{\mathrm{MR}}$ would be attributed to cardiomyopathy.

When interpreting the results of this study, it is important to keep in mind that $\mathrm{COD}_{\mathrm{MR}}$ and $\mathrm{COD}_{\mathrm{DC}}$ have been assessed in different ways. To obtain causes of death from HL and $\mathrm{BC}$ patients, we reviewed the medical files. If the cause of death could not be retrieved, a questionnaire was sent to the patient's GP. Thus, where Statistics Netherlands has to rely on the physician who fills in the death certificate, in our research setting, we were able to utilize more information from medical records to obtain $\mathrm{COD}_{\mathrm{MR}}$. Acknowledging these differences between $\mathrm{COD}_{\mathrm{MR}}$ and $\mathrm{COD}_{\mathrm{DC}}$, the question arises what level of agreement can be reached when comparing $\mathrm{COD}_{\mathrm{MR}}$ and $\mathrm{COD}_{\mathrm{DC}}$. Statistics Netherlands previously assessed the reliability of coding an underlying cause of death from death certificates. ${ }^{16}$ The reliability of the cause-of-death statistics, assessed by coding the same death certificate by different registration clerks, ranged from high $(>90 \%)$ for major causes 
of death such as cancers and acute myocardial infarction to low $(<70 \%)$ for chronic diseases. In the current study, we observed an overall agreement for common causes of death of $71 \%$ in HL patients and $92 \%$ in BC patients. Relating these findings to the reliability study of Statistics Netherlands, the level of agreement in the current study is comparable with known variability in determining cause of death.

Among HL patients, our most important finding was that $\mathrm{COD}_{\mathrm{MR}}$ was more often attributed to cardiovascular disease, whereas $\mathrm{COD}_{\mathrm{DC}}$ was more often attributed to HL. This indicates that HL is more often recorded in the causeof-death statistics files than we would expect from a clinical perspective, leading to an overestimation of mortality from HL. Our comparison between $\mathrm{COD}_{\mathrm{MR}}$ and $\mathrm{COD}_{\mathrm{DC}}$ showed that discrepancies were more frequent within the HL cohort than those in the $\mathrm{BC}$ cohort. BC patients most often died from $\mathrm{BC}$ itself within a short period of time, whereas a substantial number of HL patients died years after the initial HL diagnosis. Although there are differences between $\mathrm{HL}$ and $\mathrm{BC}$ patients in the calendar period of cancer diagnosis, follow-up time, and age at treatment, discrepancies in cause of death appear to be more frequent when deaths occurred after a relatively long period of follow-up, when the likelihood of deaths due to late adverse events related to treatment is higher.

\section{Conclusion}

We observed high levels of agreement between $\mathrm{COD}_{\mathrm{MR}}$ and $\mathrm{COD}_{\mathrm{DC}}$ for common causes of death in HL and BC patients. However, differences were observed in the attribution of HL and circulatory disease as causes of death between $\mathrm{COD}_{\mathrm{MR}}$ and $\mathrm{COD}_{\mathrm{DC}}$. Observed discrepancies between $\mathrm{COD}_{\mathrm{MR}}$ and $\mathrm{COD}_{\mathrm{DC}}$ frequently occurred in the presence of late effects of treatment for $\mathrm{HL}$; $\mathrm{HL}$ was more often recorded as $\mathrm{COD}_{\mathrm{DC}}$, whereas the $\mathrm{COD}_{\mathrm{MR}}$ more often concerned potential late effects of treatment. In future studies, researchers should keep in mind that differences in causes of death may arise when examining long-term mortality in cancer patients using different sources of cause-of-death data.

\section{Disclosure}

The authors report no conflicts of interest in this work.

\section{References}

1. Johansson LA, Westerling R. Comparing Swedish hospital discharge records with death certificates: implications for mortality statistics. Int J Epidemiol. 2000;29(3):495-502.

2. Johansson LA, Westerling R. Comparing hospital discharge records with death certificates: can the differences be explained? J Epidemiol Community Health. 2002;56(4):301-308.

3. Johansson LA, Björkenstam C, Westerling R. Unexplained differences between hospital and mortality data indicated mistakes in death certification: an investigation of 1,094 deaths in Sweden during 1995. J Clin Epidemiol. 2009;62(11):1202-1209.

4. Klijs B, Nusselder WJ, Mackenbach JP. Nationwide individual record linkage study showed poor agreement of causes of death and hospital diagnoses at individual level but reasonable agreement at population level. J Clin Epidemiol. 2014;67(2):160-168.

5. Schaffar R, Rapiti E, Rachet B, Woods L. Accuracy of cause of death data routinely recorded in a population-based cancer registry: impact on cause-specific survival and validation using the Geneva Cancer Registry. BMC Cancer. 2013;13:609.

6. Aleman BM, van den Belt-Dusebout AW, Klokman WJ, van't Veer MB, Bartelink H, van Leeuwen FE. Long-term cause-specific mortality of patients treated for Hodgkin's disease. J Clin Oncol. 2003;21(18):3431-3439.

7. $\mathrm{Ng} \mathrm{AK}$, Bernardo MP, Weller E, et al. Long-term survival and competing causes of death in patients with early-stage Hodgkin's disease treated at age 50 or younger. $J$ Clin Oncol. 2002;20(8):2101-2108.

8. Hooning MJ, Aleman BM, van Rosmalen AJ, Kuenen MA, Klijn JG, van Leeuwen FE. Cause-specific mortality in long-term survivors of breast cancer: a 25-year follow-up study. International journal of radiation oncology, biology. Physics. 2006;64(4):1081-1091.

9. van Leeuwen FE, Klokman WJ, Hagenbeek A, et al. Second cancer risk following Hodgkin's disease: a 20-year follow-up study. J Clin Oncol. 1994;12(2):312-325.

10. van Leeuwen FE, Klokman WJ, Veer MB, et al. Long-term risk of second malignancy in survivors of Hodgkin's disease treated during adolescence or young adulthood. J Clin Oncol. 2000;18(3):487-497.

11. de Bruin ML, Burgers JA, Baas P, et al. Malignant mesothelioma after radiation treatment for Hodgkin lymphoma. Blood. 2009;113(16):3679-3681.

12. Aleman BM, van den Belt-Dusebout AW, de Bruin ML, et al. Late cardiotoxicity after treatment for Hodgkin lymphoma. Blood. 2007;109(5):1878-1886.

13. van Nimwegen FA, Schaapveld M, Janus CP, et al. Cardiovascular disease after Hodgkin lymphoma treatment: 40-year disease risk. JAMA Intern Med. 2015;175(6):1007-1017.

14. Boekel NB, Jacobse JN, Schaapveld M, et al. Cardiovascular disease incidence associated with internal mammary chain irradiation and other breast cancer treatments: a large cohort study of patients treated from 1970 through 2009. Br J Cancer. Epub 2018 Aug 1.

15. Organization WH. ICD-10: International Statistical Classification of Diseases and Related Health Problems. Geneva: WHO; 1992-1994.

16. Harteloh P, de Bruin K, Kardaun J. The reliability of cause-of-death coding in The Netherlands. Eur J Epidemiol. 2010;25(8):531-538.

17. van Sonsbeek JLA. Van de schaduw des doods tot een licht ten leven. De historie van de methodiek van de doodsoorzakenstatistiek in Nederland 1865-2005 [From the shadow of death to a light of life. The history of the methodology of cause-of-death statistics in the Netherlands 1865-2005]. Voorburg/Heerlen: Centraal Bureau voor de Statistiek; 2005. Dutch.

18. Landis JR, Koch GG. The measurement of observer agreement for categorical data. Biometrics. 1977;33(1):159-174. 


\section{Supplementary materials}

Table SI Causes of death according to medical records and death certificates in BC patients

\begin{tabular}{|c|c|c|c|c|c|c|c|c|}
\hline Medical records & BC & $\begin{array}{l}\text { Lung } \\
\text { cancer }\end{array}$ & $\begin{array}{l}\text { Gastrointestinal } \\
\text { cancer }\end{array}$ & $\begin{array}{l}\text { Other } \\
\text { malignant } \\
\text { neoplasms }\end{array}$ & $\begin{array}{l}\text { Circulatory } \\
\text { disease }\end{array}$ & $\begin{array}{l}\text { Other } \\
\text { causes of } \\
\text { death }\end{array}$ & $\begin{array}{l}\text { Unknown } \\
\text { and } \\
\text { unavailable }^{a}\end{array}$ & $\begin{array}{l}\text { Total } \\
\text { medical } \\
\text { records }\end{array}$ \\
\hline $\mathrm{BC}$ & 456 & 7 & 3 & 8 & 0 & 4 & 5 & 483 \\
\hline Lung cancer & 2 & 20 & 0 & 0 & 0 & 0 & 0 & 22 \\
\hline Gastrointestinal cancer & 0 & 0 & 12 & 0 & 0 & 0 & 0 & 12 \\
\hline Other malignant neoplasms & 5 & I & 2 & 25 & 0 & 1 & 0 & 32 \\
\hline Circulatory disease & 5 & 0 & 0 & 0 & 4 & 2 & 0 & 11 \\
\hline Other causes of death & 8 & 1 & 1 & 0 & 0 & 12 & 0 & 22 \\
\hline Unknown and unavailable ${ }^{\mathrm{a}}$ & 69 & 8 & 8 & 4 & 8 & 11 & 0 & 108 \\
\hline Total number in registry data & 545 & 37 & 26 & 35 & 12 & 30 & 5 & 690 \\
\hline
\end{tabular}

Notes: Cause of death according to the ICD-10: BC (C50), lung cancer (C33-C34), gastrointestinal cancer (CI5-C26), and circulatory disease (I00-199). a Unknown and unavailable causes of death include ICD-10 codes R96-R99 and cases where no information on cause of death in medical records or no response from the GP could be obtained.

Abbreviations: BC, breast cancer; GP, general practitioner

Table S2 Causes of discrepancies between causes of death from medical records and causes of death from death certificates in BC patients

\begin{tabular}{|c|c|c|}
\hline $\mathbf{n}$ & $\%$ & Comments \\
\hline \multicolumn{3}{|c|}{$\mathrm{BC}$ as cause of death from medical records } \\
\hline I & 5 & Coding error \\
\hline I & 5 & Coding error by registration clerk (“ovarian cancer" instead of "BC”) \\
\hline I & 5 & External cause of death \\
\hline I & 5 & Cause of death from medical records not mentioned on death certificate \\
\hline 19 & 21 & No explanation ${ }^{a}$ \\
\hline 9 & 47 & Malignant neoplasm stated as cause of death on death certificate, not registered in medical records \\
\hline 4 & 21 & Malignant neoplasm stated as cause of death on death certificate, registered in medical records \\
\hline 6 & 32 & Cause of death from medical records stated on death certificate, but not as underlying cause of death \\
\hline I & 5 & Cause of death from medical records related to diagnosis stated on death certificate \\
\hline 12 & 63 & Cause of death from medical records not stated on death certificate \\
\hline 21 & 100 & \\
\hline \multicolumn{3}{|c|}{$B C$ as cause of death from death certificates } \\
\hline 20 & 100 & No explanation \\
\hline 7 & 35 & Cause of death from medical records stated on death certificate, but not as underlying cause of death \\
\hline 6 & 30 & Cause of death from medical records related to diagnosis stated on death certificate \\
\hline 7 & 35 & Cause of death from medical records not stated on death certificate \\
\hline 20 & 100 & \\
\hline
\end{tabular}

Note: aNumbers do not add up to $100 \%$; multiple comments possible when no explanation was found.

Abbreviation: $\mathrm{BC}$, breast cancer.

Clinical Epidemiology

\section{Publish your work in this journal}

Clinical Epidemiology is an international, peer-reviewed, open access, online journal focusing on disease and drug epidemiology, identification of risk factors and screening procedures to develop optimal preventative initiatives and programs. Specific topics include: diagnosis, prognosis, treatment, screening, prevention, risk factor modification,
Dovepress

systematic reviews, risk and safety of medical interventions, epidemiology and biostatistical methods, and evaluation of guidelines, translational medicine, health policies and economic evaluations. The manuscript management system is completely online and includes a very quick and fair peer-review system, which is all easy to use. 